\title{
Rethinking Remediation
}

Citation for published version (APA):

Prescott-Clements, L., Voller, V., Bell, M., Nestors, N., \& van der Vleuten, C. P. M. (2017). Rethinking Remediation: A Model to Support the Detailed Diagnosis of Clinicians' Performance Problems and the Development of Effective Remediation Plans. Journal of Continuing Education in the Health Professions, 37(4), 245-254. https://doi.org/10.1097/CEH.0000000000000173

Document status and date:

Published: 01/01/2017

DOI:

10.1097/CEH.0000000000000173

Document Version:

Publisher's PDF, also known as Version of record

Document license:

Taverne

Please check the document version of this publication:

- A submitted manuscript is the version of the article upon submission and before peer-review. There can be important differences between the submitted version and the official published version of record.

People interested in the research are advised to contact the author for the final version of the publication, or visit the DOI to the publisher's website.

- The final author version and the galley proof are versions of the publication after peer review.

- The final published version features the final layout of the paper including the volume, issue and page numbers.

Link to publication

\footnotetext{
General rights rights.

- You may freely distribute the URL identifying the publication in the public portal. please follow below link for the End User Agreement:

www.umlib.nl/taverne-license

Take down policy

If you believe that this document breaches copyright please contact us at:

repository@maastrichtuniversity.nl

providing details and we will investigate your claim.
}

Copyright and moral rights for the publications made accessible in the public portal are retained by the authors and/or other copyright owners and it is a condition of accessing publications that users recognise and abide by the legal requirements associated with these

- Users may download and print one copy of any publication from the public portal for the purpose of private study or research.

- You may not further distribute the material or use it for any profit-making activity or commercial gain

If the publication is distributed under the terms of Article $25 \mathrm{fa}$ of the Dutch Copyright Act, indicated by the "Taverne" license above, 


\title{
Rethinking Remediation: A Model to Support the Detailed Diagnosis of Clinicians' Performance Problems and the Development of Effective Remediation Plans
}

\author{
Linda Prescott-Clements, PhD, PhD, MHPE (Hons), BSc, PFHEA; Vicky Voller, MA(Cantab); Mark Bell; \\ Natasha Nestors; Cees P. M. van der Vleuten, PhD
}

\begin{abstract}
The successful remediation of clinicians demonstrating poor performance in the workplace is essential to ensure the provision of safe patient care. Clinicians may develop performance problems for numerous reasons, including health, personal factors, the workplace environment, or outdated knowledge/skills. Performance problems are often complex involving multifactorial issues, encompassing knowledge, skills, and professional behaviors. It is important that (where possible and appropriate) clinicians are supported through effective remediation to return them to safe clinical practice. A review of the literature demonstrated that research into remediation is in its infancy, with little known about the effectiveness of remediation programs currently. Current strategies for the development of remediation programs are mostly "intuitive"; a few draw upon established theories to inform their approach. Similarly, although it has been established that identification of the nature/scope of performance problems through assessment is an essential first step within remediation, the need for a more widespread "diagnosis" of why the problems exist is emerging. These reasons for poor performance, particularly in the context of experienced practicing clinicians, are likely to have an impact on the potential success of remediation and should be considered within the "diagnosis." A new model for diagnosing the performance problems of the clinicians has been developed, using behavioral change theories to explore known barriers to successful remediation, such as insight, motivation, attitude, self-efficacy, and the working environment, in addition to addressing known deficits regarding knowledge and skills. This novel approach is described in this article. An initial feasibility study has demonstrated the acceptability and practical implementation of our model.
\end{abstract}

Keywords: remediation behavioral change, revalidation, competence, poor performance, insight, integrated behavioral model, performance, knowledge translation, maintenance of certification, physician assessment/remediation, problem/dyscompetent physicians, dissemination of innovations, theory of planned behavior, transtheoretical model

DOI: 10.1097/CEH.0000000000000173

\begin{abstract}
key component in the provision of high quality and safe care for patients is competent and safe clinicians working effectively within teams. Where there are deficiencies in the performance of an individual clinician, patients may be at the risk. Therefore, it is essential that performance concerns are
\end{abstract}

\footnotetext{
Disclosures: The authors declare no conflict of interest.
}

No additional funding was received (completed within the National Clinical Assessment Service as part of educational development and improvement).

Dr. Prescott-Clements: Lead Assessment and Intervention Adviser, National Clinical Assessment Service, NHS Resolution, London, United Kingdom. Ms. Voller: Director of NCAS, National Clinical Assessment Service, NHS Resolution, London, United Kingdom. Mr. Bell: Professional Support and Remediation Lead, National Clinical Assessment Service, NHS Resolution, London, United Kingdom. Ms. Nestors: Professional Support and Remediation Manager, National Clinical Assessment Service, NHS Resolution, London, United Kingdom. Prof. van der Vleuten: Professor of Education and Scientific Director of the School of Health Professions Education, Department of Educational Research and Development, Maastricht University, Maastricht, The Netherlands.

Correspondence: Linda Prescott-Clements, PhD, PhD, MHPE (Hons), BSc, PFHEA, Lead Assessment and Intervention Adviser, NCAS, NHS Resolution, 151 Buckingham Palace Road, London Sw1w 9SZ, United Kingdom; e-mail: Linda. Prescott-Clements@resolution.nhs.uk.

Copyright (c) 2017 The Alliance for Continuing Education in the Health Professions, the Association for Hospital Medical Education, and the Society for Academic Continuing Medical Education diagnosed quickly and thoroughly and addressed appropriately. Although the diagnosis of the nature and scope of a clinician's performance concerns through performance assessments has been explored extensively in medical education, in the context of remediation, there has been less focus on diagnosing the reasons "why" an individual may be underperforming in some areas, and these factors may have a significant impact on the potential effectiveness of remediation. Such reasons are likely to differ between the undergraduate setting and experienced practicing clinicians.

For practicing clinicians with identified performance problems, various bodies may be involved in the development of remediation action plans, such as their employer or contracting organization, Royal Colleges, professional regulators, or (in the United Kingdom) the National Clinical Assessment Service (NCAS) within NHS Resolution. ${ }^{1}$ Given the investment of resources associated with the development and implementation of any remediation action plan, it is essential that the approaches used and interventions involved are evidence based and effective in achieving long-term positive change in terms of improved clinical practice and them being fit for purpose (ie, sufficiently competent to perform within their role/job). 
This article describes the development of a new model for the development of remediation action plans for clinicians with performance problems based on established theory, and the rationale for this approach based on the evidence available. We began by reviewing the medical education literature to explore the existing approaches to remediation, reported effectiveness, and underlying theories these were based upon. Then, we considered the nature of performance problems of clinicians accessing NCAS' support in order to identify appropriate theories on which to base our approach, with the aim of maximizing effectiveness in terms of achieving long-term, improved, clinical performance in the workplace.

The clinicians accessing the services of NCAS are usually practicing at a senior level (ie, consultants) and have a significant amount of experience. NCAS cases also represent all clinical specialties within primary and secondary care and a wide range of workplace settings.

We focus specifically on the development of remediation plans for individual clinicians with performance problems, which have already been established through robust assessment processes (Fig. 1). ${ }^{1}$ However, the further exploration of the nature of the performance problems and possible causes (ie, "diagnosis" of the problems) is a key feature of our proposed model (Fig. 1). The results of an initial feasibility study conducted to identify the acceptability of the model for developing remediation plans to stakeholders and its practical implementation are also reported.

\section{REMEDIATION: WHAT IS EFFECTIVE?}

Despite a number of emerging publications over the past year, it is notable that the literature on the effectiveness of remediation in medical education remains limited. There is a lack of published evidence to support the effectiveness of approaches to remediation at all educational levels but especially for postqualification/practicing clinicians. ${ }^{2-5} \mathrm{We}$ found just two literature reviews that focused specifically on remediation within medical education, ${ }^{2,3}$ both of which highlight the small-scale or relatively low-quality evidence of studies available and the urgent need for more research in this area. A further systematic review has been published more recently, focusing upon the use of workplace-based assessment in identifying and remediating underperformance in medical trainees (graduate medical education). ${ }^{5}$ This review also highlights the lack of studies focusing on remediation. ${ }^{5}$

In addition to the lack of available evidence regarding the effectiveness of interventions for remediation, only a few of the approaches reported using relevant educational (or other) theories. $^{2}$ Only 8 of 31 studies reviewed by Cleland et $\mathrm{al}^{2}$ were identified to have referred to educational theory, three of these being linked, describing learning theory on cognition and metacognition. ${ }^{6}$

Remediation interventions in the context of undergraduate or early postgraduate medical education were almost all based on instructional teaching strategies (didactic teaching), targeting primarily knowledge and skills (or both), frequently because of poor examination results. ${ }^{2,3}$ Consequently, most remediation interventions were considered to represent "more of the same" in terms of teaching/interventions, although the few studies describing a more holistic approach to interventions such as the provision of learner support appeared to be more likely to report a positive effect. $^{2}$

A number of models for remediation have been proposed, presenting some common features. ${ }^{3,7,8}$ Hauer et $\mathrm{al}^{3}$ performed a thematic review of the remediation literature (only a few studies focused on practicing physicians): a four-step model for remediation was proposed that included the following: (1) the use of multiple assessment tools to identify deficiencies in performance; (2) diagnosis of the deficiency and identification of an individualized learning plan; (3) instruction/interventions with the provision of opportunities for deliberate practice, feedback, and reflection; and (4) focused reassessment. ${ }^{3}$ More recently, Krzyzaniak et $\mathrm{al}^{7}$ have explored the perceptions of experienced medical educators regarding methods of effective remediation in graduate medical education in order to inform the development of a holistic framework for developing plans for struggling residents. This model also describes four stages: (1) identification of the struggling resident (through objective and subjective means); (2) clarification of the scope of the problem and recognition of secondary factors contributing to poor performance; (3) intervention-comprising feedback, learning plan, and confounders; and (4) reassessment. Although Boileau et $\mathrm{al}^{8}$ focused their model around the identification of poor performance and planning of remediation, similarities are evident in the approach they proposed that clinical teachers should adopt to address learners difficulties: (1) detecting a problem based on subjective impression, (2) gathering and documenting objective data, (3) assessing data to make a diagnosis, and (4) planning remediation.

A consistent message within the literature (and evident from our own experience) is that in order to be effective, remediation interventions should be targeted to the specific requirements of the individual student or clinician, particularly in the context of addressing poor performance of registered or licensed doctors in practice. ${ }^{3,9-11}$ Yet, with regard to the "diagnosis" of the performance problem, the message is less clear. Most studies describe the diagnosis of poor performance primarily around the identification of suboptimal practice through multiple modes of assessment, in order to provide a clear picture of "what" needs to be remediated. However, the need to consider other factors associated with "why" the performance problem might exist is beginning to emerge. Boileau et $\mathrm{al}^{8} \mathrm{recommended}$ that when making a pedagogical diagnosis of the performance problem, "cognitive, attitudinal, and mental health issues" should also be considered. In terms of attitudinal issues, their literature review identified examples such as ignorance of professional responsibilities, values, and beliefs, poor insight or self-regulation, insufficient motivation, and conflicts in the workplace. On the other hand, Krzyzaniak et $\mathrm{al}^{7}$ described the need to recognize "secondary factors contributing to poor performance" during the clarification stage, including situational, personal (health or social), or professional stressors. The consideration of issues associated with "why" a performance problem exists, in addition to the identification of "what" that problem is begins to explores the wider context of the individual clinician's circumstances, recognizing that such issues may be a potential barrier to successful remediation.

\section{Potential Barriers to Successful Remediation}

A number of potential barriers to effective remediation have been described, which tend to be associated with the 


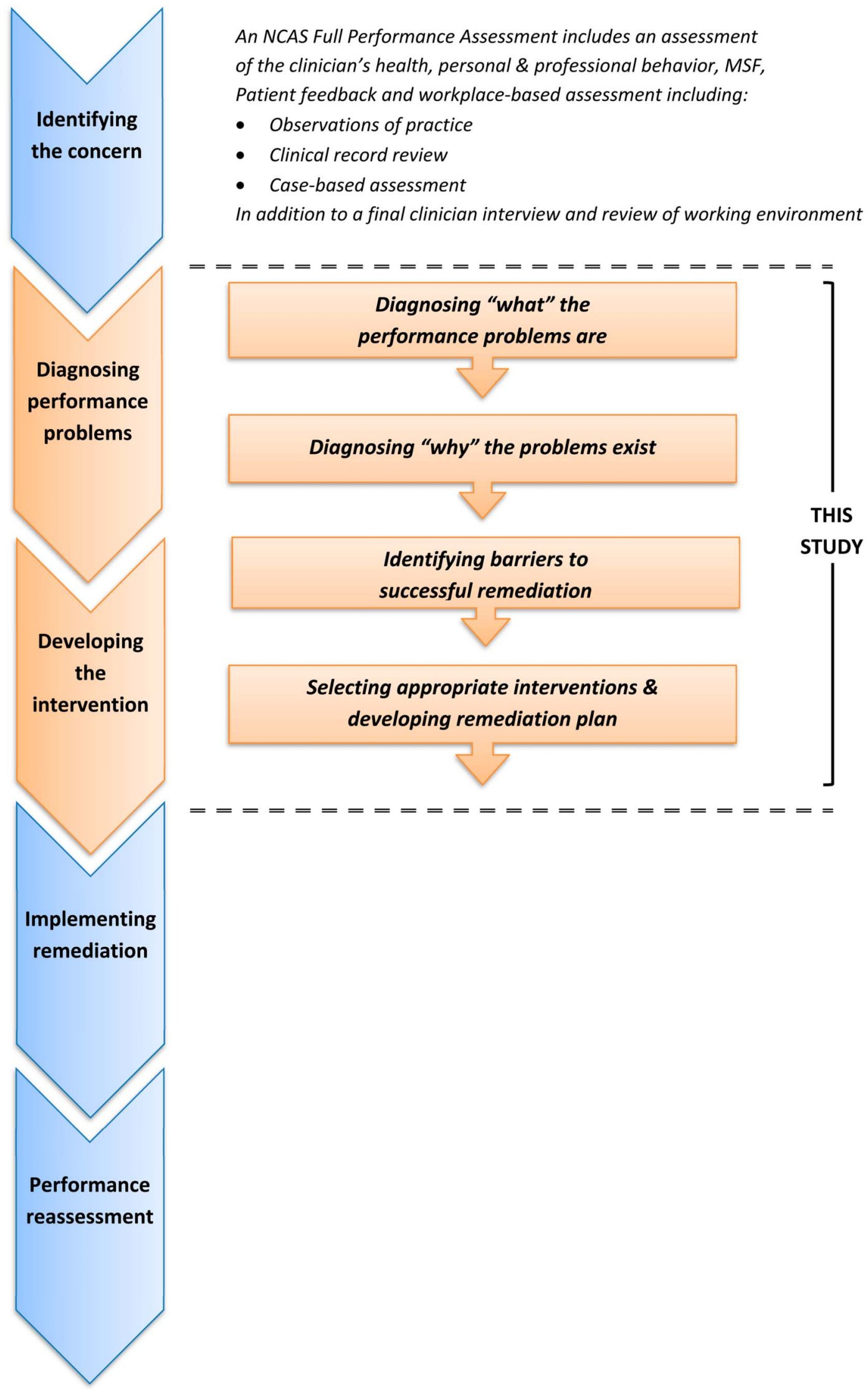

FIGURE 1. Steps in the development of remediation for clinicians. MSF, Multi-Source Feedback. 
characteristics of the individual clinician or the working environment rather than with the design of remediation or the content (ie, specific interventions used). These align closely with the elements associated with successful outcomes identified in the literature on learning transfer. ${ }^{12-15}$ Clinician age (ie, older clinicians) has been associated with poor outcomes of remediation, with potential causes including cognitive decline or health concerns or reduced motivation to engage with the intervention. ${ }^{4,10,16}$ The workplace environment and/ or clinical context are also important considerations when developing remediation interventions because the organizational structure, culture, team dynamics, and support mechanisms available may influence the success of remediation or otherwise. $^{4,17}$ A number of publications highlight the important role of an individual's motivation for, and engagement with, the remediation intervention or program in determining success. ${ }^{2,4,6,10,16}$ Although an association between extrinsic motivation (via the mandatory participation in remediation programs) has been described, it is evident that intrinsic motivation is likely to have a key role in determining success. In remediation programs for poorly performing clinicians implemented by licensing authorities in Canada, mandatory attendance and high stakes consequences were regarded as a motivating factor, which may contribute to the success of the program, ${ }^{10}$ although a smaller study involving clinicians with significant deficiencies noted that while mandatory participation ensured compliance and attendance, it did not necessarily ensure engagement, and those who did not improve or performance deteriorated further were observed to be "more passive" or "less active in participation." ${ }^{16}$ It has also been suggested that extrinsic and intrinsic motivation may be linked: Winston et al ${ }^{6,18}$ noted that "at-risk" medical students often failed to seek support via the voluntary remediation programs on offer, but when [a degree] of attendance was mandatory, this increased the likelihood students becoming engaged with a supportive program that they recognized as helping them. Had the program been voluntary, they may not have attended and failed to engage, and a positive association between the extent of sessions attended and success was noted. It has also been established that insight into poor performance (ie, the recognition of the need to change and selfawareness) may also impact on motivation and engagement with remediation programs. ${ }^{7,18}$ Poorly performing clinicians/ students may fail to recognize that they lack competence or initially be "in denial," resulting in low intrinsic motivation to attend remediation because of not seeing any benefits to doing so. ${ }^{18}$ Similarly, a lack of self-efficacy or confidence can be encountered by individuals who are performing poorly (suggesting a degree of insight), which can also reduce intrinsic motivation to engage with remediation through negative feelings about ability, unless addressed quickly through support. ${ }^{2,18}$

Although the more recent models for developing remediation plans recommend the exploration of secondary factors that might clarify the cause of the performance problem and certain barriers to successful remediation as part of the initial diagnosis, this is currently described in terms of a general approach implemented through discussion with the medical trainee rather than any formal structured assessment. ${ }^{7,8}$ Furthermore, the models proposed do not refer to established learning or behavioral theories.

\section{THE NATURE OF PERFORMANCE CONCERNS IN PRACTICING CLINICIANS}

In order for it to be effective, it is essential that any remediation plan considers the personal and professional context of the individual clinician. Perhaps, unsurprisingly, the nature of performance problems reported differs between the undergraduate and postgraduate setting.

Suboptimal performance of medical students is most often associated with academic knowledge (identified after poor examination or assessment results) and/or clinical skills (for senior students). ${ }^{2,3}$ The performance concerns identified in practicing doctors (including residents) tend to present as multifactorial issues involving aspects of knowledge, skills, attitudes, and behaviors, and seldom present as a single problem or concern. ${ }^{3,11,19}$ A Canadian study reporting on remediation programs for physicians referred to the Quebec medical licensing authority over a 10 -year period $(n=305)$ noted that a range of performance concerns were presented, including therapeutic knowledge $(37 \%)$, diagnostic knowledge $(32 \%)$, record keeping $(14 \%)$, technical skills $(10 \%)$, clinical judgement $(5 \%)$, and communication skills (2\%). ${ }^{6}$ In New Zealand, a smaller study involving 24 doctors required to undergo remediation by the Medical Council of New Zealand indicated that all of the doctors involved had more than one issue of concern upon initial assessment, including record keeping $(65 \%)$, communication $(52 \%)$, organizational $(48 \%)$, clinical knowledge $(43 \%)$, clinical reasoning $(43 \%)$, and prescribing $(39 \%) .^{11}$

In the United Kingdom, clinicians assessed by NCAS usually present with multifactorial performance concerns. An analysis of the first 50 assessment cases conducted between April 2002 and December 2003 identified a range of problems under the headings "clinical care," "behavior" (including communication, leadership, management) "health," “education/training/ CPD," and "organizational issues," with all but one case involving three or more performance concerns. Although clinical performance problems were evident in more than $80 \%$ of the cases, communication and behavioral problems were also noted in around half of the cases. ${ }^{18}$ A more recent analysis of 205 NCAS full-performance assessments between 2007 and 2014 further supported the multifaceted and complex nature of identified problems (internal data).

\section{MOVING BEYOND KNOWLEDGE AND SKILLS . . ADDRESSING BEHAVIORS}

The differences reported above, between the knowledge/skillsbased deficiencies of medical students and the more complex multifactorial issues arising in clinicians working in clinical practice, further highlight the importance of context when considering the competence and performance of clinicians. The distinction between "competence" and "performance" has been described, with "performance" being what the clinician does in actual practice (ie, their behavior); this is a consequence of multiple factors extending beyond the application of knowledge and skills involving personal factors (such as attitudes, motivations, and beliefs) and environmental factors in the workplace (such as organizational policy, team dynamics, and workload). ${ }^{15,20,21}$

A number of studies exploring the effectiveness of continuing professional development (CPD) or continuing medical education have indicated that despite regular attendance at such 
activities, changes in clinical practice (behavior) are rare. ${ }^{17,22,23}$ Analysis of the objectives of 110 accredited CPD activities demonstrated that $96 \%$ of the 404 learning objectives targeted the cognitive domain, mostly around knowledge and comprehension. Only $1.5 \%$ of the objectives targeted the affective domain (ie, feelings, motivations, attitudes, and values that guide behavior and decisions). ${ }^{23}$ Similarly, a study comparing evidence-based practice of occupational therapists before and after a multifaceted educational intervention showed that although the participants' knowledge increased significantly after the intervention and was maintained, the behavior of the clinicians changed very little. ${ }^{22}$ The authors suggested that in order to improve clinical practice, and the consistent application of knowledge and skills, educational interventions should also target the noncognitive domains. ${ }^{17,22}$

It is clear how additional focus on noncognitive factors of a clinician with performance problems is important when determining an appropriate remediation plan. Noncognitive factors with the potential to influence a change in a clinician's performance in practice include their personal values, attitudes, motivations, personal agency, and salience of the activity, $6,18,24$ insight, ${ }^{4,7}$ and environmental/organizational factors. ${ }^{4,18}$ Furthermore, studies into the professionalism of clinicians describe their professional behaviors, and how these may be driven by personal values, attitudes, and other noncognitive factors. ${ }^{25,26}$

There is further evidence to support the importance of considering clinicians' behaviors from the knowledge translation and health care improvement literature involving specific interventions. In a study exploring the implementation of two clinical decision rules in emergency medicine diagnostic imaging in Canada, clinicians' attitudes were significantly associated with the intention to perform the behavior in both settings, although intention was only associated with actual behavior in one setting, suggesting other factors may also have a role in the successful implementation of such guidelines. ${ }^{27}$ Similarly, a number of behavioral factors were able to predict evidencebased practice with regard to providing diabetes care in the United Kingdom, including attitude, intention, habit, and selfefficacy. ${ }^{28}$ A review of the evidence of why clinicians do not follow clinical guidelines identified a number of noncognitive factors that presented a barrier to optimal performance, including personal agreement with the guidelines, self efficacy, poor motivation/habit, and a range of factors associated with the workplace environment such as lack of time or resources. ${ }^{29}$ More recently, in a randomized clinical trial to identify whether certain behavioral interventions had an impact on clinicians' adherence to prescribing guidelines, it was discovered that the use of accountable justification (a prompt for the clinician to insert free-text justification for prescribing) and peer comparison (receipt of an e-mail comparing their prescribing rate with "top performers") resulted in lower rates of inappropriate prescribing. ${ }^{30}$

In the context of clinicians with performance concerns accessing support from NCAS in the United Kingdom, we explored a number of cases involving common performance concerns from the perspective of both cognitive and noncognitive domains. It became clear that various factors, personal or environmental, could contribute (individually or in combination) to specific deficiencies in performance. For example, clinicians identified as maintaining poor patient records: they may not have the knowledge about what constitutes a "detailed, contemporaneous clinical record" if they have not seen or understood General Medical Council (GMC) guidance or they may not perform adequately in this area because of attitude/motivation such as apathy, habit, or workplace environmental factors, such as workload or lack of time.

\section{A MODEL FOR AN ENHANCED APPROACH TO REMEDIATION}

A review of existing remediation programs for doctors in the literature demonstrated that although most described the benefits of developing a personalized action plan, almost none had drawn upon established theory, and the design was generally intuitive, based on identified deficiencies in performance and focusing primarily on knowledge and skills., ${ }^{2,4} \mathrm{~A}$ notable exception is the work by Winston et $\mathrm{al}^{6}{ }^{6}$ which draws on a number of learning theories when developing a remediation program for medical students. While this and a number of other studies describe the importance of student/clinician personal engagement with the program, their motivation to improve, or the potential impact of environmental factors, these are not explicitly explored and addressed in the development of the remediation program on an individual basis. ${ }^{3,6,10,11,16,24}$

In order to maximize the likelihood that poorly performing clinicians are able to remediate and return to safe and effective clinical practice, we have developed an enhanced approach to the development of individual remediation plans for NCAS, which takes account of both cognitive and noncognitive factors impacting upon performance. Although addressing deficiencies in only knowledge and skills may support development in terms of competence, without consideration of the noncognitive issues in parallel, this may be unlikely to result in lasting change within the workplace particularly if the primary reason for the initial concern was associated with the personal motivation, values, or attitudes of the clinician.

In order to achieve this, we have drawn upon established behavioral change theories. Our approach for developing remediation plans is primarily based upon the integrated behavior model (IBM), with additional constructs added around clinician "insight" and identification of the readiness for behavior change (originating from the transtheoretical model). ${ }^{31-33}$

The IBM (Fig. 2) incorporates constructs from the theory of reasoned action and the theory of planned behavior, addressing motivation for behavior change and intention to change (ie, attitude, perceived norm, and personal agency), with four other important components: knowledge and skills to perform the behavior, environmental constraints that could create a barrier to the individual performing the behavior, the salience of the behavior to the individual, and the opportunity to practice and make the new behavior habitual. ${ }^{32}$ In addition to the constructs within IBM, we also added a further dimension known to be potential barrier to remediation: the clinician's insight into his or her performance problems, and whether he or she agree that behavioral change is indeed needed. If a clinician has no insight into his or her deficiencies or disagrees with the outcomes of assessment highlighting poor performance, this will inevitably impact on his or her motivation and behavioral intention. In order to address this more explicitly in our model, we added this construct using the stages of change described in the 


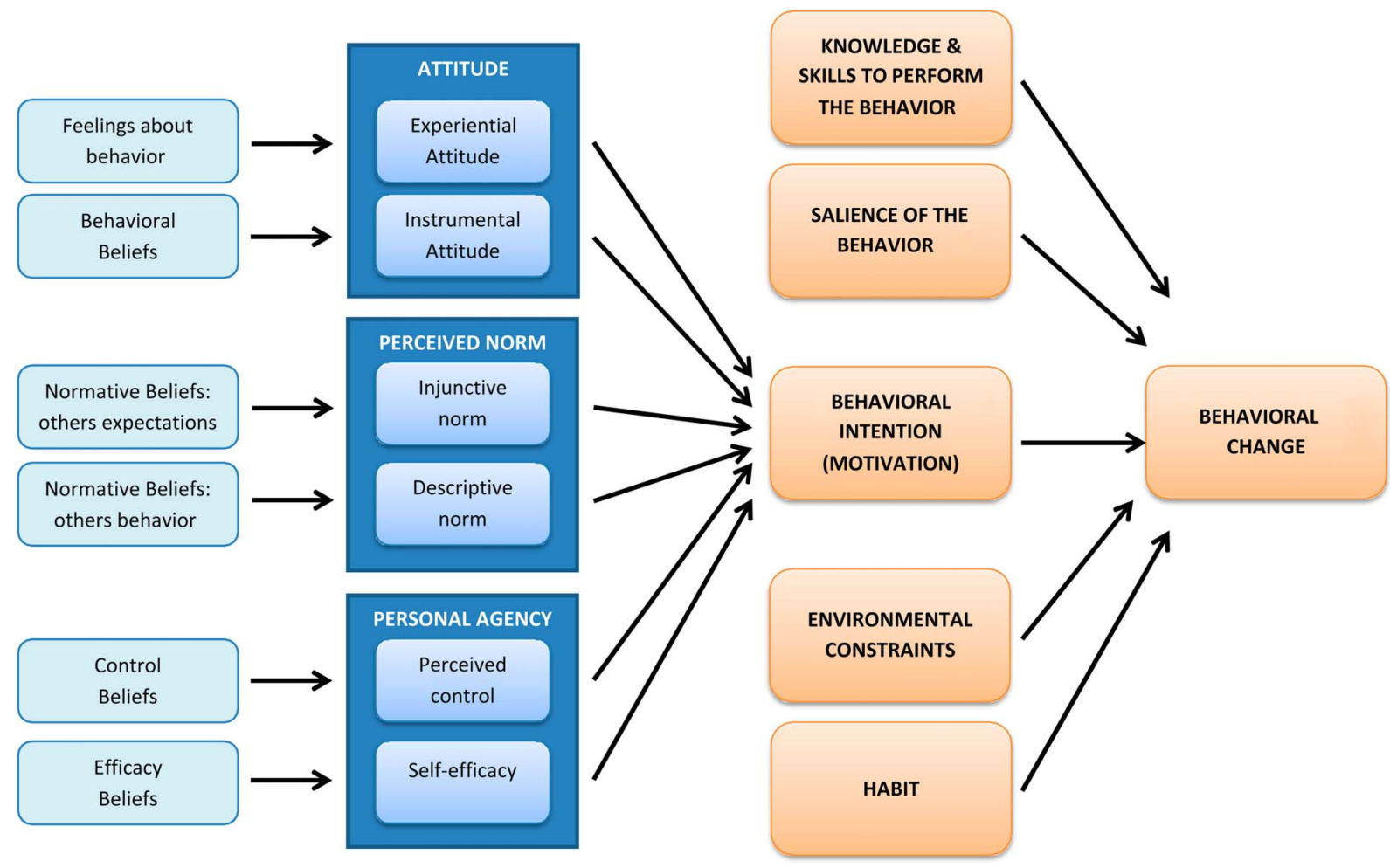

FIGURE 2. Integrated behavior model ${ }^{32}$

transtheoretical model: Precontemplation, Contemplation, Preparation, and Action as a framework (Table 1). ${ }^{31,33}$ We also acknowledge the role of personal and social external variables underpinning the theory of reasoned action and theory of planned behavior, which are particularly relevant in this context, such as age, gender, race, ethnicity, religion, culture, and intelligence, and the situational moderators encompassed within overall environmental constraints. ${ }^{32,34}$

Although the NCAS assessment ${ }^{1}$ process involves a behavioral assessment, which may explore some of these issues as part of the initial diagnosis of the performance concerns, this further exploration of the clinician's perceptions, insight, and attitudes toward behavioral change in the context of remediation are proposed because these may change when they are presented with the results from a fully independent assessment of their abilities. For example, a clinician lacking insight prior to being assessed may develop insight because of a comprehensive assessment process involving independent peers, and in terms of behavioral change, they may progress from "pre- contemplation" prior to being assessed to "contemplation" or "preparation" after the results are presented and reflected upon.

Model for Developing Remediation Action Plans

The model we developed has three stages:

Stage 1: Developing the questions for semistructured discussions with individual clinicians and their employer.

Stage 2: Data collection

2a. Interview with the clinician

2 b. Semistructured discussion with the employer

Stage 3: Triangulation and development of the remediation program

Each stage is described below.

A distinctive feature of this model is that it incorporates a theory-based list of key constructs to (1) support the "diagnosis" or "clarification" stages of remediating clinicians and (2)

\section{TABLE 1.}

\section{Overarching Stages of Change Used to Inform the Development of NCAS Remediation Programs}

\begin{tabular}{|c|c|}
\hline Stage of Change & \\
\hline Precontemplation & $\begin{array}{l}\text { No immediate intention to change behavior. Individuals lacking insight are likely to be in this stage, and interventions to } \\
\text { develop insight and/or acceptance of performance problems should be targeted within the remediation plan. }\end{array}$ \\
\hline Contemplation & Individual's intend to change behavior and are generally considering the pros and cons of doing so. \\
\hline Action & Individuals have already begun to change their behavior in some way and may be looking for additional support. \\
\hline
\end{tabular}

Source: adapted from Prochaska et al.$^{33}$ 


\section{TABLE 2}

Template to Facilitate Structured Discussions With the Clinician and Employer, Using Constructs to Inform the Development of Remediation Plans

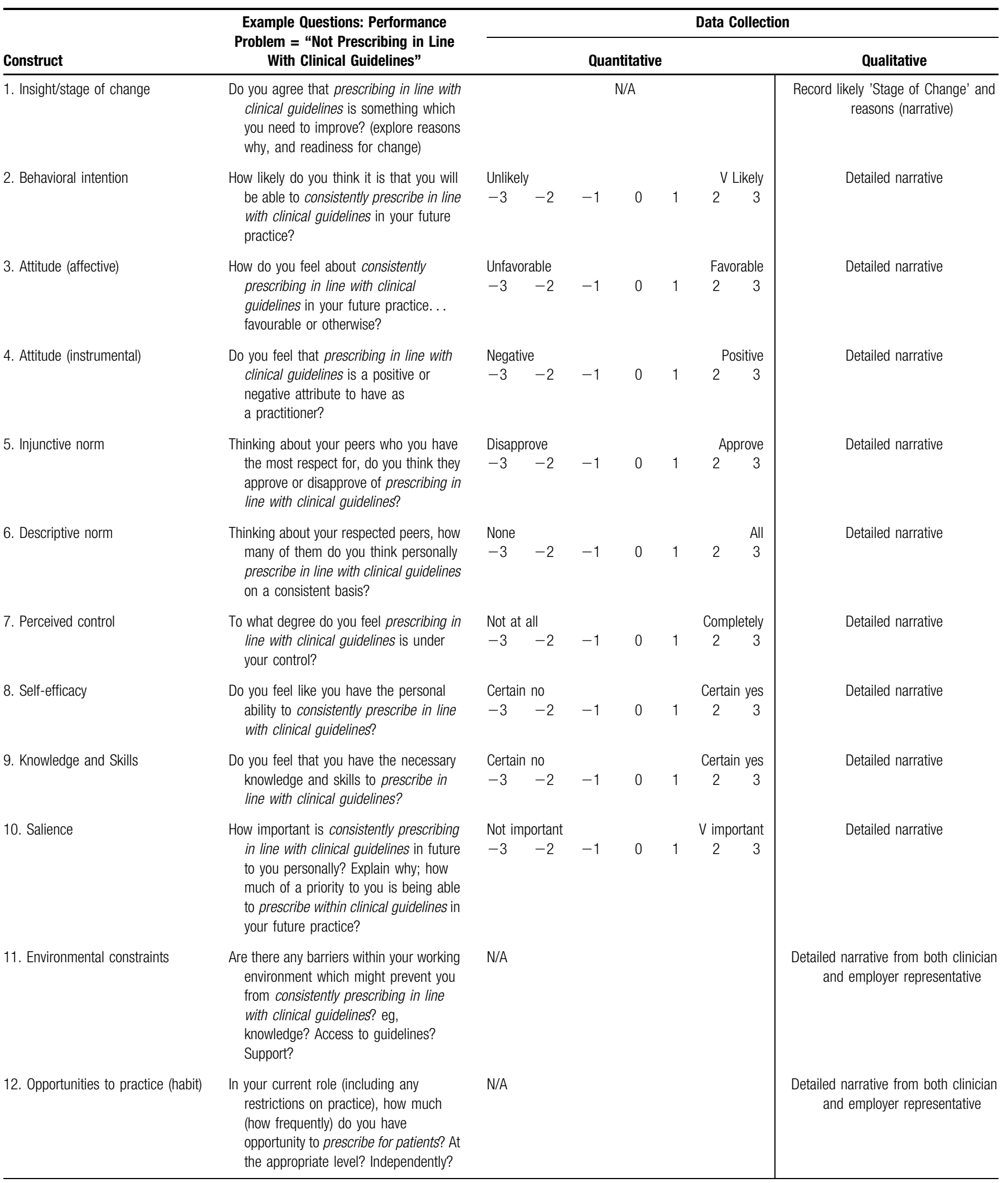

V, very; N/A, Not Applicable. 
provide a stronger evidence base for the identification of interventions most likely to lead to effective remediation of clinicians with performance problems (Fig. 2).

Using the theories described above, we developed a list comprising 12 constructs (Table 2) to support and guide exploratory discussions with the clinician. In addition, constructs 11 and 12 provide guidance for discussions with the clinician's employer. The purpose of the discussions with the clinician is to elicit information regarding the clinician's personal attitudes, motivations, and insight and environmental constraints, which may be a potential barrier to effective remediation and long-term improved performance. The purpose of the discussion with the employer is to identify potential barriers associated with the workplace environment. Each construct is measured directly (indirect measures are not included) for the key performance problem domains identified by the evidence collected and triangulated during the NCAS assessment process (a comprehensive workplace-based assessment comprising multiple performance assessment tools, including observations, review of clinical records, case-based questioning, and peer and patient feedback across the full scope of clinical practice addressing knowledge, skills, and attitudes). The priority within the discussion process is to record rich qualitative data, which can be used to inform the identification of appropriate interventions to support remediation. Constructs 2 to 10 also include a quantitative measure using a bipolar scale, to add a degree of perspective to the narrative, and support our longitudinal evaluation of the approach. Through revisiting these discussions and constructs at milestones within the remediation plan, any changes in these noncognitive factors can be measured.

On completion and transcription of the semistructured discussions with the clinician and employer, this information is triangulated with other "diagnostic" evidence available from the NCAS assessment. When developing the remediation plan for the clinician, the aim is to address potential barriers to remediation identified through the semistructured discussions and deficiencies in knowledge and skills, through appropriate interventions and support mechanisms, such as coaching, mentoring, and feedback. For example, a clinician identified as not routinely following clinical guidelines in practice, describing negative feelings for construct 2 (behavioral intention) and construct 6 (descriptive norm), perhaps indicating that they believe their peers do not consistently follow clinical guidelines either, the remediation plan might reasonably include peer discussions and audit data around this issue to address these feelings, before other interventions targeting knowledge or skills. Similarly, where environmental constraints are identified as a potential barrier to change (eg, poor access to latest clinical guidelines), this can be addressed in the remediation plan.

The steps within our approach are described below.

\section{Stage 1: Developing the Questions for Semistructured Discussions With Individual Clinicians and Their Employer}

The 12 constructs are used to develop questions for use in semistructured discussions with the clinician and his or her employer. A template including sample questions and text for each of the 12 constructs was developed to facilitate this process (Table 2). Using the constructs to develop questions rather than using a predetermined list of questions helps to ensure that the questions reflect the specific performance problems of each individual clinician. Accordingly, the questions for each construct are developed following a review of the evidence of what the performance problem obtained from the comprehensive assessment of their clinical practice. In practice, this involves performing a thematic analysis of the NCAS assessment report findings, to identify overarching "domains" upon which the discussion questions could be focused (eg, "engaging with clinical team members," which may incorporate communication, teamwork, and leadership deficiencies or "assessing complex patient conditions including comorbidity," which may include deficiencies in procedural elements such as history taking, as well as knowledge and clinical decision making). Once the domains have been identified, they are used to develop specific questions for each of the constructs in the template. An effort is made to select no more than four domains to keep the length of the discussions with clinicians manageable.

Stage 2a: Semistructured Discussion With the Clinician The aim of the semistructured discussion is to explore each of the constructs in as much depth as possible for each domain of poor performance. Obtaining a detailed narrative is prioritized over getting a quantitative rating for each construct. Discussions begin with a description of the process and explanation that the discussion is intended to identify potential barriers to successful remediation in order that these can be addressed if possible as part of the plan. All clinicians are informed that the information gathered is confidential and will be used only to inform the development of their remediation plan. Consent is then sought to proceed with the discussion on this basis.

Discussions are expected to take 15 to 60 minutes depending on the number and complexity of the domains covered. Due to the geographic dispersion of clinicians in the United Kingdom, discussions are usually held via telephone. However, videoconferencing or face-to-face discussions may be recommended for more complex cases involving multifaceted performance concerns.

Stage 2b: Semistructured Discussion With the Employer Discussions with a representative for the employer/contracting organization focus on exploring potential barriers to remediation of the clinician that might be associated with the workplace environment, that is, construct 11 (potential environmental constraints) and construct 12 (opportunities to practice). When potential issues in these areas are identified by the clinician (eg, reduced opportunity to see rare or complex cases), possible solutions can be explored. Employer discussions are usually relatively short, lasting around 10 to 15 minutes.

\section{Stage 3: Triangulation and Development of the Remediation Program}

Once the discussions have been transcribed, a member of the NCAS Assessment and Intervention team considers any personal, environmental, attitudinal, and behavioral issues that may impact the potential for successful remediation (positive or negative), alongside evidence gathered through assessment on the nature and scope of the performance problems. Potential barriers to successful long-term remediation emerging from the clinician and employer discussions (eg, lack of insight, negative behavioral intention or feelings of low self-efficacy) are targeted through support/interventions at the beginning of the 
remediation action plan, before addressing the cognitive elements associated with the diagnosis of the problem (ie, knowledge and skills). Such interventions may include targeted coaching, mentoring, or other types of support identified to address the relevant issues (eg, improve insight, motivation, and likely engagement with the action plan). The rationale for this approach is that if a clinician identifies as not being ready to change his or her performance, demonstrates a lack of insight or expresses feelings of low self-efficacy, simply sending him or her to a CPD course or initiating skills training in the area may improve competence but not his or her performance (ie, sustained behavior in the workplace) in the longer term. Information from other constructs can shed light on the reasons for the lack of insight, such as negative feelings associated with instrumental attitude or about descriptive norm (Table 2). In such cases, the intervention can be tailored to address this barrier using approaches, such as peer discussions, audit or reference data, and personal coaching, to further develop insight.

\section{TESTING THE FEASIBILITY OF THE INTEGRATED BEHAVIOR MODEL ON REMEDIATION (IBMR) FOR THE DEVELOPMENT OF ACTION PLANS}

A feasibility study was conducted to test the acceptability of the IBMR with stakeholders and its practical implementation within the context of supporting clinicians accessing support from NCAS. In line with the focus for feasibility studies described by Bowen et al, ${ }^{35}$ the purpose was to explore satisfaction of the new approach (including the semistructured discussion with the clinician and employer) and perceived appropriateness, as well as the resources involved in successful implementation and time frames for the development of remediation plans.

The new approach was tested with clinicians accessing NCAS remediation support between January and March 2016 $(n=6)$. Three of the clinicians required comprehensive remediation programs following the identification of multifaceted performance problems by an NCAS full-performance assessment, whereas the other three clinicians needed generic action plans following a prolonged period of absence from clinical practice (which may or may not be associated with performance concerns). Clinicians were from a range of primary and secondary care settings.

Stakeholder feedback regarding the acceptability and implementation of the approach was gathered in semistructured interviews with participants (clinicians and employer/contractor representatives involved in the semistructured telephone discussions). Feedback was obtained regarding the acceptability of the semistructured discussion, perceived appropriateness, perceived helpfulness to the process of developing their remediation plan, and the time taken to perform the discussion. Feedback regarding the practical implementation of the model was also obtained from team members conducting the semistructured discussions.

In all cases, the clinicians and employers agreed to the semistructured discussions and tended to be open in their responses. In each case, the discussions elicited issues for consideration relevant to the content of the remediation plan, which might not have otherwise been known and which was useful in deter- mining interventions for support, in addition to the extent of support required in some cases. In terms of implementation, it was determined that the time frame for developing the remediation plan was inevitably associated with the responsiveness and availability of the clinician and employer to hold semistructured discussions with NCAS.

\section{CONCLUSION}

In this article, we describe a new model (IBMR) to support the development of remediation action plans for clinicians with identified performance problems, which further supports the diagnosis of the problem (in terms of "why" the problem exists) and informs the identification of effective interventions that have the potential to support the clinician into long-term improved practice.

To our knowledge, IBMR is the first model that uses constructs derived from established behavioral change theories, incorporating both cognitive and noncognitive factors associated with the remediation of performance problems. Furthermore, in the context of remediating clinical performance problems of experienced clinicians, this new approach introduces the concept that the identification of potential noncognitive barriers to successful remediation with the view to addressing them if possible through targeted support or interventions may increase the effectiveness of remediation of $\operatorname{cog}$ nitive elements (ie, knowledge and skills) in terms of long-term performance in the workplace.

The next stage of this work is to perform a longitudinal evaluation of the model to determine the effectiveness of the method and impact upon the remediation of clinicians. Through systematic follow-up and evaluation of construct data, we will attempt to identify the constructs most likely to predict successful—or unsuccessful-remediation.

\section{Lessons for Practice}

- Performance concerns identified in practicing clinicians are usually complex and multifactorial, involving behaviors in addition to knowledge, skills, and attitudes.

- Barriers to remediation include the clinician's insight, motivation, and attitude toward the behavior, in addition to contextual factors and the workplace environment: these factors should be considered-in addition to deficiencies in knowledge and skills-when fully diagnosing the performance problems and developing remediation plans.

- Exploration of potential barriers to remediation (behavioral and within the workplace environment) with the clinician and employer can elicit valuable information, which can be used to identify appropriate interventions and strategies to support the remediation plan.

\section{REFERENCES}

1. NHS Resolution and NCAS. How we work. Available at: http://www. ncas.nhs.uk/. Accessed October 23, 2017. 
2. Cleland J, Leggate H, Sandards J, et al. The remediation challenge: theoretical and methodological insights from a systematic review. Med Educ. 2013;47:242-251.

3. Hauer KE, Ciccone A, Henzel TR, et al. Remediation of the deficiencies of physicians across the continuum from medical school to practice: a thematic review of the literature. Acad Med. 2009;84:1822-1832.

4. Humphrey C. Assessment and remediation for physicians with suspected performance problems: an international survey. J Contin Educ Health Prof. 2010;30:26-36.

5. Barrett A, Galvin R, Steinert Y, et al. BEME review of the use of workplace-based assessment in identifying and remediating under performance among postgraduate medical trainees: BEME Guide No. 43. Med Teach. 2016;38:1188-1198.

6. Winston KA, van der Vleuten CPM, Scherpbier AJJA. At-risk medical students: implications of students' voice for the theory and practice of remediation. Med Educ. 2010;44:1038-1047.

7. Krzyzaniak SM, Wolf SJ, Byyny R, et al. A qualitative study of medical educators' perspectives on remediation: adopting a holistic approach to struggling residents. Med Teach. 2017;39:967-974.

8. Boileau L. St-Onge C, Audetat MC. Is there a way for clinical teachers to assist struggling learners? A synthetic review of the literature. Adv Med Educ Pract. 2017;8:89-97.

9. Goulet F, Jacques A, Gagnon R. An innovative approach to remedial continuing medical education, 1992-2002. Acad Med. 2005;80:533-540.

10. Goulet F, Gagnon R, Gingras ME. Influence of remedial professional development programs for poorly performing physicians. J Contin Educ Health Prof. 2007;27:42-48.

11. Lillis S, Takai N, Francis S. Long term outcomes of a remedial education program for doctors with clinical performance deficits. J Contin Education Health Prof. 2014;34:96-101.

12. Baldwin TT, Ford JK. Transfer of training: a review and directions for future research. Personal Psychol. 1988;41:63-105.

13. De Rijdt C, Stes A, van der Vleuten C, et al. Influencing variables and moderators of transfer of learning to the workplace within the area of staff development in higher education: research review. Educ Res Rev. 2013;8:48-74.

14. van den Eertwegh V, van Dulmen S, van Dalen J, et al. Learning in context: identifying gaps in research on the transfer of medical communication skills to the clinical workplace. Patient Educ Couns. 2013;90:184-192.

15. Grossman R, Salas E. The transfer of training: what really matters. Int J Train Develop. 2011;15:103-120.

16. Hanna E, Premi J, Turnbull J. Results of remedial continuing medical education in dyscompetent physicians. Acad Med. 2000;75:174-176.

17. Grol R. Changing physicians' competence and performance: finding the balance between the individual and the organisation. J Contin Educ Health Prof. 2002;22:244-251.

18. Winston KA, van der Vleuten CPM, Scherpbier AJJA. An investigation into the design and effectiveness of a mandatory cognitive skills programme for at-risk medical students. Med Teach. 2010;32:236-243.

19. Berrow D, Faw L, Jobanputra R. Analysis of the First 50 NCAS Assessment Cases: NCAS Evaluation, Research \& Development; 2005. Available at http://www.ncas.nhs.uk/publications/. Accessed October 23, 2017.
20. Rethans JJ, Norcini JJ, Baron-Maldonado M, et al. The relationship between competence and performance: implications for assessing practice performance. Med Educ. 2002;36:901-909.

21. NCAS Report. Understanding performance difficulties in doctors. 2004 Available at: http:/www.google.co.uk/url? sa=t\&rct=j\&q=\&esrc=s\& source $=$ web $\& c d=1 \&$ cad $=$ rja $\&$ uact $=8 \&$ ved $=0$ ahUKEwjK6on -69 nUAh WJQBoKHdrCApoQFggnMAA\&url=http \%3A\%2F\%2Fwww.ncas.nhs. uk\%2FEasySiteWeb\%2FGatewayLink.aspx \%3FalId\%3D9371\&usg=A FQjCNEuN0yAARoSyZfZ3Smb6wigR4QqtQ. Accessed October 23, 2017.

22. McClusky A, Lovarini M. Providing education on evidence based practice improved knowledge but did not change behaviour: a before and after study. BMC Med Educ. 2005;5:40.

23. Legare F, Freitas A, Thompson-Leduc P, et al. The majority of accredited continuing professional development activities do not target clinical behaviour change. Acad Med. 2015;90:197-202.

24. Billet S. Learning through health care work: premises, contributions and practices. Med Educ. 2016;50:124-131.

25. Van Mook WNKA, Gorter SL, Kieboom W, et al. Poor professionalism identified through investigation of unsolicited healthcare components. Postgrad Med J. 2012;88:443-450.

26. Barnhoorn PC, van Mook WNKA. Professionalism or professiona behaviour: no reason to choose between the two. Med Educ. 2015 49:740.

27. Perez R, Brehaut JC, Taljaard M, et al. Theory of planned behaviour can help understand processes underlying the use of two emergency medicine diagnostic imaging rules. Implementation Sci. 2014;9:88.

28. Presseau J, Johnston M, Francis JJ, et al. Theory-based predictors of multiple clinician behaviours in the management of diabetes. J Behav Med. 2014;37:607-620.

29. Cabana MD, Rand CJ, Powe NR, et al. Why don't physicians follow clinical guidelines? A framework for improvement. JAMA. 1999;282. 1458-1465.

30. Meeker D, Linder JA, Fox CR, et al. Effect of behavioral interventions on inappropriate antibiotic prescribing among primary care practices: a randomized clinical trial. JAMA. 2016;315:562-570.

31. Cilliers F, Schuwirth L, van der Vleuten C. Health behaviour theories: a conceptual lens to explore behaviour change. In: Cleland J, Durning SJ, eds. Researching Medical Education. 1st ed. West Sussex, UK: John Wiley \& Sons; 2015:141-153.

32. Montano DE, Kasprzyk D. Theory of reasoned action, theory of planned behaviour and the integrated behaviour model. In: Glanz K, Rimer BK, Viswanath K, eds. Health Behaviour and Health Education: Theory, Research \& Practice. 4th ed. San Fransisco, CA: Jossey-Bass; 2008:67-92.

33. Prochaska JO, Redding CA, Evers KE. The transtheoretical model and stages of change. In: Glanz K, Rimer BK, Viswanath K, eds. Health Behaviour and Health Education: Theory, Research \& Practice. 4th ed. San Fransisco, CA: Jossey-Bass; 2008:97-121.

34. Ajzen I. Attitudes, Personality and Behaviour. 2nd ed. Open University Press; 2011.

35. Bowen DJ, Kreuter M, Spring B, Cofta-Woerpel L, Linnan L, Weiner D, Fernandez M. How we design feasibility studies. Am J Prev Med. 2009, $36: 452-457$ 